\title{
Detection and quantification of T-cell subpopulations and NK cells in peripheral blood from healthy individuals
}

\author{
Israel Parra-Ortega ${ }^{1}$, Karen S. Salceda-Rangel', Noemi Nájera-Martínez ${ }^{1}$, Briceida López-Martínez¹,
} Vianney Ortiz-Navarrete ${ }^{2}$ and Irlanda Olvera-Gómez ${ }^{3,4 *}$

${ }^{1}$ Laboratorio Clínico, Hospital Infantil de México Federico Gómez; ${ }^{2 B}$ Biomedicina Molecular, Centro de Investigación y de Estudios Avanzados del Instituto Politécnico Nacional (CINVESTAV); ${ }^{3}$ Universidad Anáhuac México Norte; ${ }^{4}$ Hospitales Federales de Referencia, Secretaría de Salud (SSA); Hospital Nacional Homeopático, Unidad 160. Mexico City, Mexico

\begin{abstract}
Background: The knowledge of the participation of different subpopulations of T lymphocytes in various pathologies helps to make therapeutic decisions, having as reference the presence of the different subpopulations of the $T$ lymphocytes associated with the disease. Methods: A profile standardization of surface molecules for the characterization of subpopulations of $T$ cells was conducted: naive, activated and memory, as well as natural killer (CD3-CD56+) cells in peripheral blöd of clinically healthy individuals. Results: Naïve (CD3+, CD4+ or CD8+, CD45RA+, CD62L+, CCR7+), activated (CD3+, CD4+ or CD8+, CD45RA+ or CD45RO+, CD69+ and/or CRTAM+), effectors (CD3+, CD4+ o CD8+, CD45RA+, CD62L-, CCR7-), +eentral memory (CD3+, CD4+ o CD8+, CD45RO+, CD62L+, CCR7+), memory effectors (CD3+, CD4+ or CD8+, CD62RO+, CD62L-, CCR7-) subpopulations were analyzed by flow cytometry. Descriptive statistics parameters were calculated (minimum values, maximum values, mean values, median). Conclusions: This panel can be very useful for monitoring patients in whom the immunological status from a cellular perspective is needed. Particularly, it can support the follow-up of patients who require an immunological reconstitution (T-cell component) evaluation.
\end{abstract}

Key words: T lymphocyte. Lymphocyte subpopulation. Flow cytometry.

\section{Determinación y cuantificación de subpoblaciones de linfocitos $T$ y células natural killer en sangre periférica de individuos sanos por citometría de flujo}

\section{Resumen}

Introducción: La determinación de las diferentes subpoblaciones de los linfocitos $T$ en las diversas patologías y el monitoreo postratamiento ayuda a que el médico tome decisiones terapéuticas teniendo como referencia la cinética de los linfocitos $T$ localizados en sangre periférica. Métodos: Se realizó la estandarización de un perfil de moléculas de superficie para la caracterización de subpoblaciones de linfocitos T: naive, activados y de memoria, así como las células natural killer o asesinnas naturales (CD3-CD56+) en sangre periférica de individuos clínicamente sanos. Resultados: Se identificaron las subpoblaciones de linfocitos: naive (CD3+, CD4+ o CD8+, CD45RA+, CD62L+, CCR7+), activados (CD3+, CD4+ o CD8+, CD45RA+ o CD45RO+, CD69+ y/o CRTAM+), efectores (CD3+, CD4+ o CD8+, CD45RA+, CD62L-, CCR7-), de memoria central (CD 3+, CD4+ o CD8+, CD45RO+, CD62L+, CCR7+) y de memoria efectora (CD3+, CD4+ o CD8+, CD45RO+, CD62L-, CCR7-) en 
las poblaciones de linfocitos T CD4+ y CD8+. Se integraron los datos obtenidos con estadística descriptiva (valores mínimos, valores máximos, media, mediana). Conclusiones: Este panel será de gran utilidad para monitorear pacientes en quienes se requiera valorar el estado inmunológico desde el punto de vista celular. Particularmente, puede apoyar en el seguimienté de los pacientes en los que se requiera evaluar la reconstitución inmunológica (componente celular de estirpe T).

Palabras clave: Linfocito T. Subpoblación de linfocitos. Citometría de flujo.

\section{Introduction}

T lymphocytes are cells of the adaptive immune system that mature in the thymus from common lymphoid progenitors, which arise from the bone marrow. The subpopulations of CD4 and CD8 T cells leave the thymus and travel through the lymphatic system to populate secondary lymphoid organs such as spleen and lymph nodes. ${ }^{1,2}$

For several decades, the number of molecules that allow identifying different subpopulations of $T$ cells from the naïve phenotype to the central and effector memory compartments has increased, including the activation state and the effectors of lymphocytes that are detectable in peripheral blood. ${ }^{3}$ Next, the identified peripheral populations will be described.

\section{Naïve or virgin T lymphocytes}

Mature lymphocytes that leave the thymus lodge mainly in the secondary lymphoid organs. The expression of the CD45RA isoform (an isoform with higher molecular weight, since it retains the expression of the three CD45 exons) is one of the primary and oldest markers for its selection. Also, the expression of adhesion molecules such as CD62L (which binds to E-selectin) and chemokine receptors such as CCR7 (two ligands have been identified for this receptor, CCL19, and CCL12) conform the naïve phenotype. Naïve T cells are located in the secondary lymphoid organs, where the professional antigen-presenting cells (dendritic cells) present the peptides as molecules of the major histocompatibility complex (MHC) class I, mainly if they are intracellular antigens, they activate CD8 $\mathrm{T}$ cells or $\mathrm{MHC}$ class II (mainly if they are extracellular antigens), which, in turn, activate CD4 T cells. ${ }^{3-6}$

\section{Activated T lymphocytes}

The recognition of the processed antigen leads to intracellular changes, such as the release of calcium stores, translocation of transcription factors to the nucleus, among others, in addition to the modification of the expression of surface molecules. This state, known as activation, is associated with a decreased expression of the CD45RA isoform, the appearance of the CD45RO molecule (an isoform of lower molecular weight that binds to CD22, a protein found in the membrane of B lymphocytes), the reduction of CD62 L and the appearance of the T-cell associated molecule restricted to class I MHC, known as CRTAM (class-I MHC-restricted T-cell associated molecule) and CD69. These two molecules have a similar expression pattern: the maximum level of expression is reached appioximately 16 to 18 hours post-activation, this expression is transient (meaning that the cells stop expressingthe molecules after some time), so they are referred as early activation markers. The expression of these molecules in humans and mice occurs exclusively in activated T cells. ${ }^{7-9}$ In the case of the chemokine receptor CCR7 (associated with the T lymphocytes retention in lymphoid organs), a low to no expression in activated T cells was reported..$^{10}$ However, it has been found that CD8+ T cells, after being activated by a specific antigen model (meaning, a monoclonal activation), express CCR7. ${ }^{11}$ One of the characteristics of in vivo activation is that both the microenvironment (cytokines in the extracellular medium) and the intensity of the received activation (affinity and avidity) have influence, such as the case of CCR7 since it can be found in post-activation antigen-specific cells expressing this molecule.

Activated lymphocytes migrate from secondary 掞phoid organs to the rest of the organism, mainly to the site where the damage or danger signal is detected (usually an area with the presence of inflammation), besides being present in peripheral blood. ${ }^{12}$ Activated T cells can be found both in the CD45RA + population, which are the recently activated and in the CD45RO+ cells which are the memory ones due to reactivation.

\section{Effector T lymphocytes}

After activation, $T$ lymphocytes acquire effector functions. In the case of CD4+ T cells, the production of cytokines that can polarize the rest of the immune-response is identified. Populations that mainly produce interferon-gamma (IFN- $\gamma)$ and tumor necrosis 
factor-alpha (TNF- $\alpha)$ (Th1, proinflammatory), IL-17 (Th17), IL-9 (Th9) and IL-4 and IL -10 (Th2, anti-inflammatory) can be differentiated.

CD8+ T cells produce cytokines such as TNF- $\alpha$ and IFN- $\gamma$ and have a cytotoxic capacity to eliminate infected or tumor cells through molecules such as granzyme $B$ and perforin. ${ }^{11}$ The phenotype of the effector T cells is CD45RA + CD62L-CCR7-. The absence of expression of molecules associated with the cells' retention in lymphoid organs, CCR7 and CD62L, favors their migration to the site of inflammation to perform their effector functions.

\section{Memory T Iymphocytes}

If the activation of naive $T$ cells is appropriate, the generation of a memory population will be induced. These cells are located mainly in the secondary lymphoid organs and peripheral blood.

In humans, the CD45RO molecule is used as a marker to select the population of cells that are a progeny of a naivve $\mathrm{T}$ lymphocyte activated through its receptor, the $T$ cell receptor. ${ }^{13,14}$

The presence or absence of the CCR7 and CD62L molecules on the surface together provide two phenotypes:

1) CMT (central memory $T$ cells): CD45RO+CD62L+ CCR7+

2) EMT (effector memory $T$ cells): $C D 45 R O+C D 62 L-$ CCR7- ${ }^{-15}$

CMT are mainly found in the secondary lymphoid organs and maintain the effector memory $T$ cell compartment. ${ }^{16}$ In contrast, EMT are those cells that, in response to a subsequent encounter with the pathogen, respond immediately with a higher effector capacity (produce large cytokines amounts in a short period) compared to the effector cells from the first differentiation of the activated naive cells. These cells are mainly circulating in the body ${ }^{14-17}$ due to the absence of CCR7 and CD62L molecules.

\section{Natural killer cells}

Natural killer (NK) cells are lymphocytes generated from a common lymphoid precursor, whose effector function is mediated by the production of cytokines, especially of high amounts of IFN- $\gamma$, and by their cytotoxic activity to eliminate infected or tumor cells. These cells are located in the peripheral blood, lymph nodes, skin, intestine, liver, lungs, uterus, and other tissues. Morphologically they are similar to $\mathrm{T}$ lymphocytes, but their surface markers are CD16+CD56+ in the absence of CD3.

In order to identify the different populations and subpopulations of lymphocytes, techniques such as density gradient centrifugation have been developed..$^{18}$ However, it is not possible to differentiate naive or activated cells only by their density or morphology, for which other methods that detect membrane proteins as markers are used. ${ }^{19}$

The development of hybridoma technology allowed producing monoclonal antibodies capable of recognizing unique epitopes of cell surface molecules and, therefore, represent a breakthrough in the identification of cellular phenotypes, either by manual or automated techniques, in addition to multiple staining. ${ }^{20}$ Flow cytometry. $\overline{\text { is }}$ of great importance in the fields of hematology and immunology for the complete analysis and detailed characterization of blood cells. ${ }^{21}$ Among the most common clinical applications of these methods is the characterization of leukocytes in primary or secondary immunodeficiency states, as in the case of infection by the human immunodeficiency virus ${ }^{22,23}$ and onco-hematological disêases. ${ }^{24}$ The development of a large number of fluorochromes should be added, which are used to covalently bind to the monoclonal antibodies used in these techniques and thus stain multiple molecules for their preeise determination in a heterogeneous cell suspension.

Therefore, it is essential to implement the determination and quantification of the different subpopulations of the T lymphocytes, as well as to know their association with the patient's clinical state. Thus, the physician will be able to integrate the results, signs, and symptoms for therapeutic decision making on the basis of the presence of different subpopulations of Tymphocytes associated with the condition.

In this research paper, a diagnosis of surface molecules was standardized for the characterization of subpopulations of T lymphocytes: naïve, activated, effectors, and central and effector memory, in addition to NK cells, in peripheral blood of clinically healthy individerals through flow cytometry.

\section{Methods}

\section{Samples}

Peripheral blood samples collected in tubes with the anticoagulant ethylenediaminetetraacetic acid (ED̈TTA) were obtained by venipuncture of 20 clinically healthy individuals (CHI) of Mexican nationality, who did not have any inflammatory process (for example infections, 
neoplasms or those under pharmacological treatment). The participants underwent a medical study to determine their health status, considering the blood count and blood chemistry values, which provided the basic parameters for the evaluation of liver, kidney, and carbohydrate and lipid metabolism function.

For the activation phenotype, the sample was obtained from an 8-year-old patient diagnosed with Epstein-Barr virus acute infection, with a viral load of 26,000 copies/ml in plasma determined by a real-time polymerase chain reaction.

Cell counting was performed by blood cytometry of each sample using an LH 780 Beckman Coulter ${ }^{\circledR}$ hematology analyzer.

\section{Immunophenotype}

For the samples staining, three test tubes of $12 \mathrm{x}$ $75 \mathrm{~mm}$ were used, one for each panel. $5 \mu$ of each panel antibody was applied (antibodies were obtained from BD Biosciences $^{\circledR}$, except anti-CRTAM antibody, obtained from Biolegend ${ }^{\circledR}$ ), and whole peripheral blood was added. For samples with a total leukocyte count between 2,000 and 13,000 cells $/ \mu \mathrm{l}, 50 \mu \mathrm{l}$ of whole peripheral blood with EDTA were placed to obtain an appropriate number of cells for the number of events acquired.

The mixture was incubated for $15 \mathrm{~min}$ at room temperature in darkness. Subsequently, $2 \mathrm{ml}$ of FACS Lysing solution (BD Biosciences ${ }^{\circledR}$ ) was added, and the mixture was incubated for $10 \mathrm{~min}$ at room temperature in darkness. Next, the tubes were centrifuged 5 min at $1800 \mathrm{rpm}$, decanted, and the cell button was washed twice with $2 \mathrm{ml}$ of FACS Flow. Finally, $350 \mu \mathrm{l}$ of cold FACS Flow (BD Biosciences ${ }^{\circledR}$ ) was added to obtain a homogeneous cell suspension.

The samples were read in the BD FACS Canto II flow cytometry system following the procedure set out in the user manual and meeting the quality standards established in the Hospital Infantil de México Federico Gómez for analytical tests with diagnostic purpose. Briefly, before sample acquisition, the equipment was calibrated and compensated with independent stains with each of the fluorochromes for correct reading, as well as unstained cells to adjust the autofluorescence. For the characterization of the different cell populations, 50,000 events were recorded.

\section{Panels for T lymphocytes phenotyping}

The fluorochromes were selected, considering that there was no overlap in their reading; this was done to
Table 1. Panel of antibodies used in the characterization of T lymphocyte subpopulations

\begin{tabular}{|c|c|c|c|}
\hline Fluorochrome & $\begin{array}{c}\text { Panel } 1 \\
\text { Naïve and memory } \\
\text { T lymphocytes }\end{array}$ & $\begin{array}{c}\text { Panel } 2 \\
\text { Activated T } \\
\text { lymphocytes }\end{array}$ & $\begin{array}{c}\text { Panel : } \\
\text { NK } \\
\text { cells }\end{array}$ \\
\hline FITC & CD45RA & CD45RA & 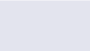 \\
\hline PE & CRTAM & CRTAM & CD16 \\
\hline Percp- Сy 5.5 & CD45RO & CD45RO & $\bar{Q}$ \\
\hline APC & CD62L & CD69 & $\operatorname{cD} 56$ \\
\hline APC H7 & $\mathrm{CD} 4$ & $\mathrm{CD} 4$ & 르 \\
\hline V450 & $\mathrm{CD} 3$ & CD3 & $\cos 3$ \\
\hline PE Cy7 & CCR7 & CD8 & 4 \\
\hline
\end{tabular}

take advantage of the three laser beams of the equipment. In the same way, monoclonal antibodies were selected.

For the CRTAM monoclonal antibody, the fluorochrome phycoerythrin was selected because CRTAM is a molecule with low levels of expression, and it was preferred to use a higher intensity fluorochrome for its detection.

Three different cell panels were made to determine naïve, activated, effector, and central and effector mèmory lymphocytes (Table 1).

\section{Data analysis}

The results were analyzed with the BD FACSDIVA ${ }^{\circledR}$ software. The graphs for the identification of each population, as well as an electronic backup copy anofthe panel template were made.

A database was constructed in which the absolute values (cells $/ \mathrm{ml}$ ) were calculated by converting the percentages using the values of total leukocytes and Rymphocytes obtained with the LH 780 Beckman Coulter $^{\circledR}$ hematology analyzer.

In the case of NK cells, the percentage of CD3CD16+CD56+ cells was obtained, and the absolute number in the total leukocyte population was also calculated. The GraphPad Prism ${ }^{\circledR} 6.01$ software for Mac OS $\mathrm{X}$ was used for the statistical analysis of the different cell populations.

\section{Results}

Twenty peripheral blood samples obtained from Mexican individuals with an age range of 8 to 18 years (average of 10 years 6 months and median of 10 years) were analyzed, of which $75 \%$ (15) were males.

From the delimitation of simple events (Fig. 1A), Size and complexity were considered to select the living 

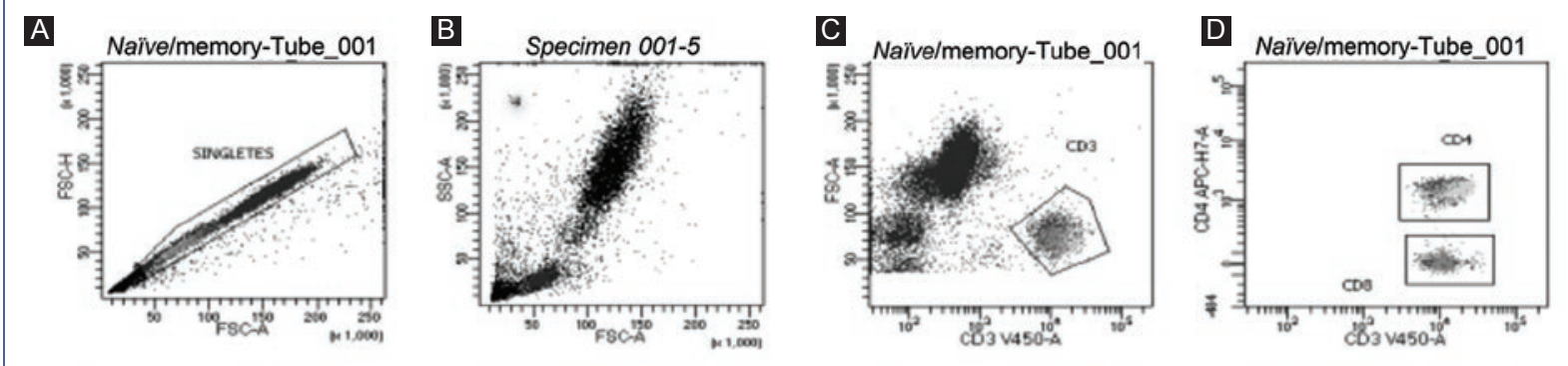

E Naïve/memory-Tube_001
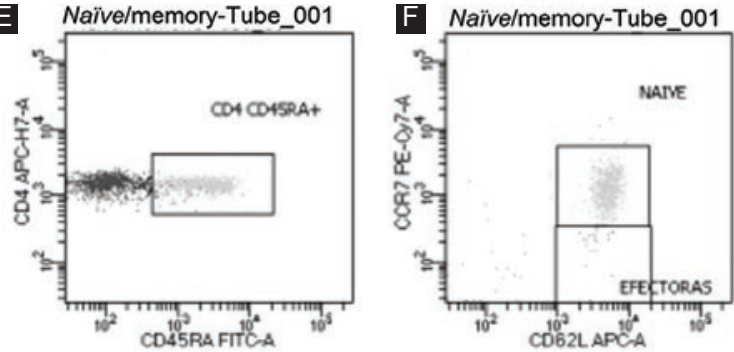

G Naïve/memory-Tube_001

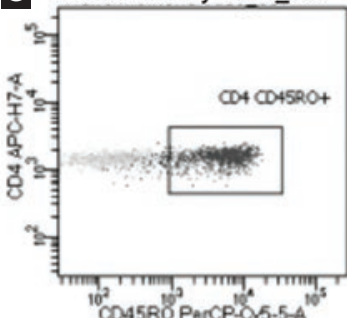

H Naïve/memory-Tube_0011
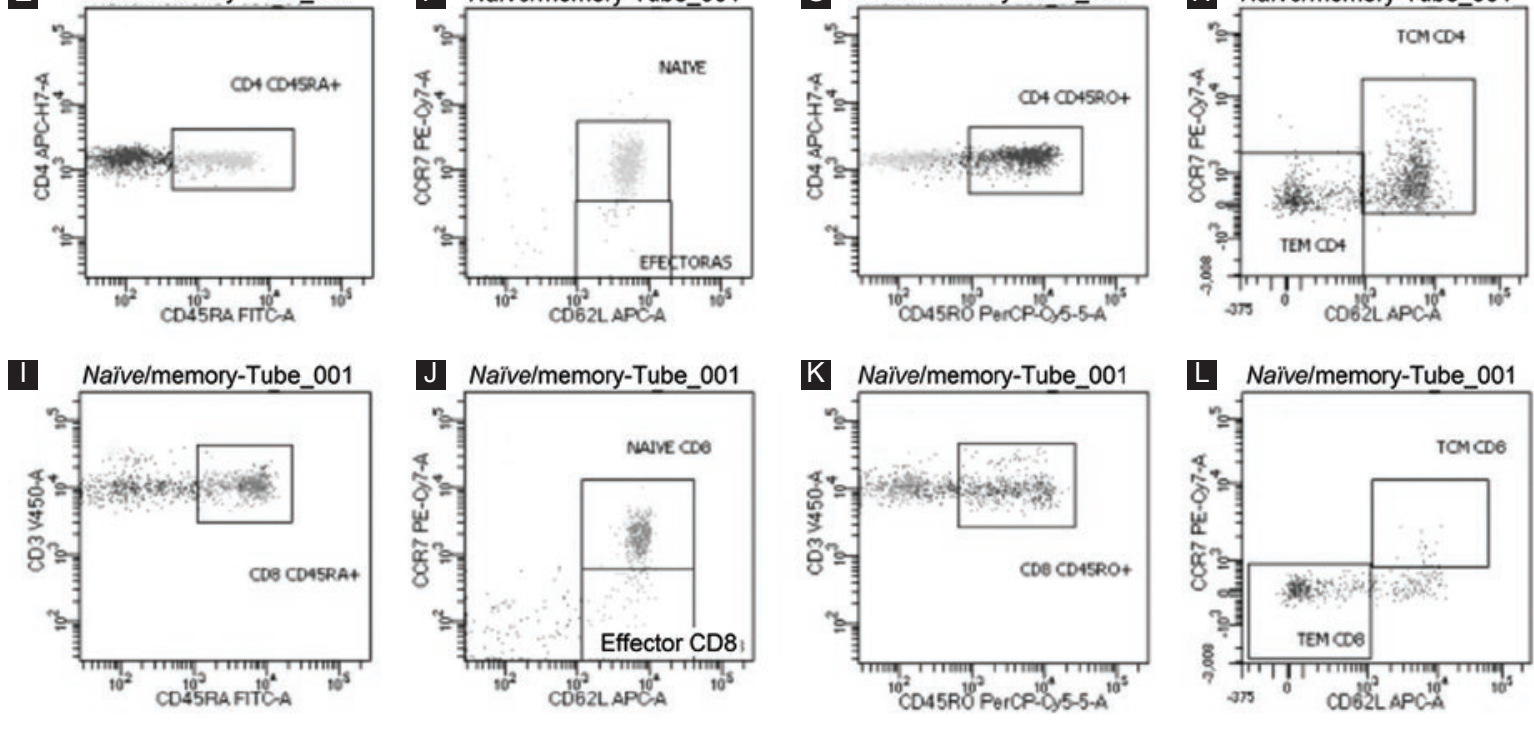

Figure 1. Phenotyping of peripheral blood T Iymphocytes. From an aliquot of a peripheral blood sample, the singlet population was delimited (A). The different populations in the peripheral blood, lymphocytes, monocytes, and granulocytes, were determined based on their size (FSC: forward scatter) and complexity (SSC: side scatter) (B). The CD3+ population was determined (C). From this population, CD4+ and CD8+ T lymphocytes were determined (D). The expression of CD45RA (E) and CD45R0 (G) molecules were considered markers of naïve and memory cells, respectively, in the population of CD4 + lymphocytes (F). From the CD45RA population (E), those cells which expressed CD62Land CCR7 were classified as naïve, and those who displayed CD62L- CCR7- as effectors (F). Meanwhile, the analysis ofthe expression of both molecules in CD45RO+ cells (G) allowed identifying central memory (CM) and effector memory (EM) cells (H). The same analysis was performed for CD8+ lymphocytes (I-L). The images shown are from a single individual and are representative of the rest of the participants included in the study.

cells (Fig. 1B). Subsequently, the population of $T$ cells was defined based on the CD3 expression (Fig. 1C); thus, the compartmentalization of CD4 + and CD8 + cells was done (Fig. 1D). The median percentage of CD3+ T cells was $20 \%$, lower than that reported in the pediatric population. ${ }^{27}$ In this region, the CD4+ and CD8+ populations were $55.3 \%$ and $47.5 \%$, respectively, and a CD4:CD8 ratio of 1.24 was obtained, similar to the findings of others. ${ }^{25}$

The different cell profiles in the populations of CD4+ and CD8+ T lymphocytes were analyzed, including naïve lymphocytes, effectors, central and effector memory (Figs. 1E-L). Using an expression profile of CD45RA+ CCR7+ CD62L+, the frequency and the absolute number of naive $T$ lymphocytes were determined, and the median values obtained were 92.60 and 67.80 for CD4+ and CD8+ $T$ cells, respectively (Tables 2 to 5 ). The naive and effector populations percentages were obtained from the CD45RA+ population.

It is possible to define the CD45RA+CCR7-CD62L- effector cells in each subpopulation by using the same staining panel. A percentage of 14.6 and 8.8 from CD $4+$ and CD8+ T cells expressing CD45RA+ was obtained, respectively (Tables 3 and 5).

The activated $\mathrm{T}$ cell phenotype was defined by those cells that expressed CD69, an early activation marker, and CRTAM, a recently described molecule that is associated with the activation state. The determination of 


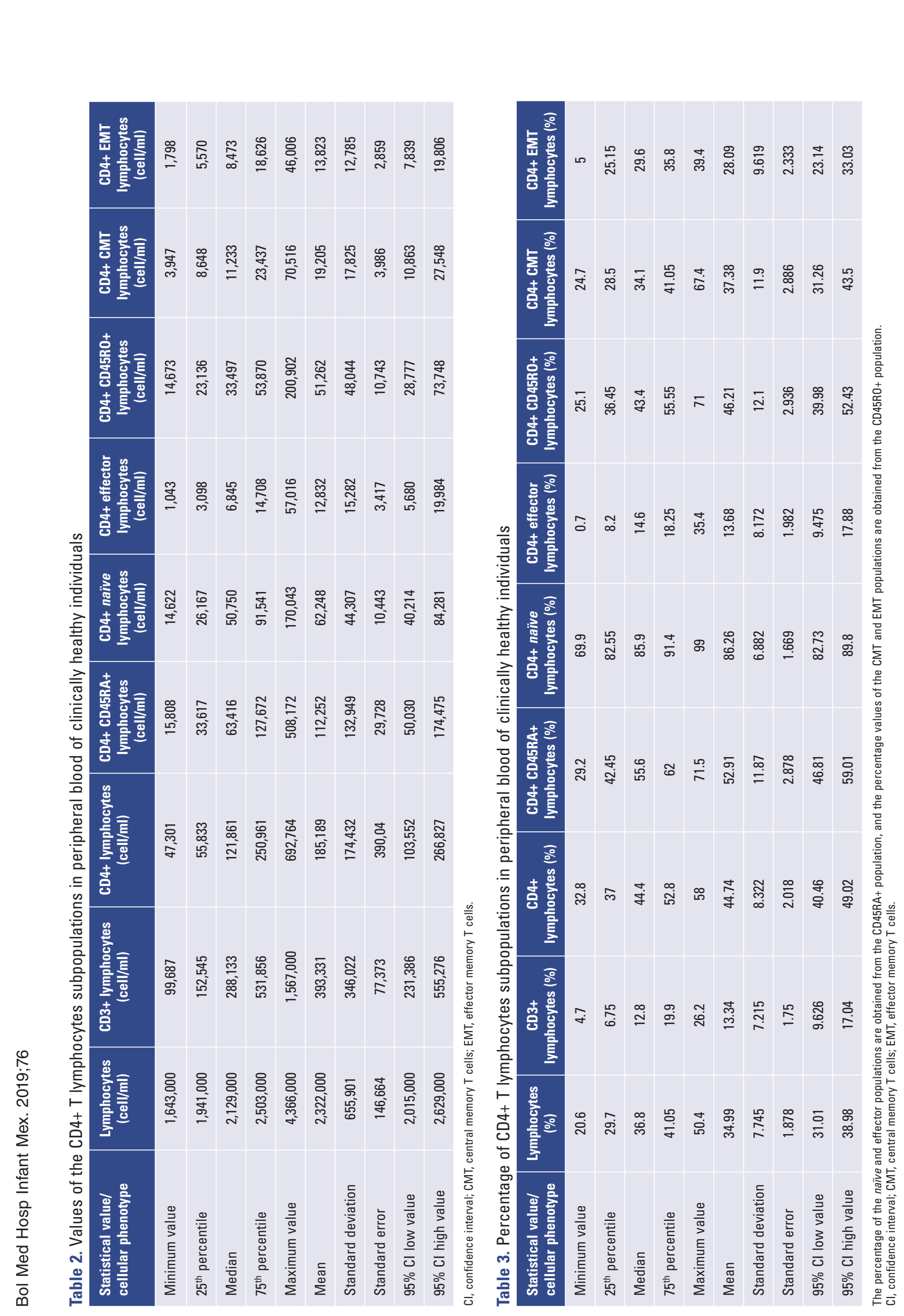


Table 4. Values of CD8+ T lymphocytes subpopulations in peripheral blood of clinically healthy individuals

\begin{tabular}{|c|c|c|c|c|c|c|c|}
\hline $\begin{array}{l}\text { Statistical } \\
\text { value/cellular } \\
\text { phenotype }\end{array}$ & $\begin{array}{c}\text { CD8+ } \\
\text { lymphocytes } \\
\text { (cell/ml) }\end{array}$ & $\begin{array}{l}\text { CD8+ CD45RA+ } \\
\text { lymphocytes } \\
\text { (cell/ml) }\end{array}$ & $\begin{array}{l}\text { CD8+ naïve } \\
\text { lymphocytes } \\
\text { (cell/ml) }\end{array}$ & $\begin{array}{l}\text { CD8+ effector } \\
\text { lymphocytes } \\
\text { (cell/ml) }\end{array}$ & $\begin{array}{c}\text { CD8+ CD45RO+ } \\
\text { lymphocytes } \\
\text { (cell/ml) }\end{array}$ & $\begin{array}{l}\text { CD8+ CMT } \\
\text { lymphocytes } \\
\text { (cell/ml) }\end{array}$ & $\begin{array}{c}\text { CD8+ EMT } \\
\text { Iymphocytes } \\
\text { (cell/mi) }\end{array}$ \\
\hline $\begin{array}{l}\text { Minimum } \\
\text { value }\end{array}$ & 36186 & 23232 & 13219 & 274.1 & 12738 & 446 & $979 \frac{\frac{\varepsilon}{L}}{\complement}$ \\
\hline $25^{\text {th }}$ percentile & 78397 & 41514 & 17440 & 1882 & 19731 & 719 & $11024^{\circ}$ \\
\hline Median & 109396 & 68644 & 35240 & 6974 & 35035 & 1931 & 25275 \\
\hline $75^{\text {th }}$ percentile & 196850 & 154529 & 63307 & 11171 & 53473 & 4201 & $38052=$ \\
\hline $\begin{array}{l}\text { Maximum } \\
\text { value }\end{array}$ & 542299 & 380694 & 148283 & 33882 & 157267 & 14592 & $12565 \overline{\overline{5}}$ \\
\hline Mean & 155947 & 110535 & 51990 & 9625 & 43701 & 3218 & 30863 \\
\hline $\begin{array}{l}\text { Standard } \\
\text { deviation }\end{array}$ & 126536 & 102996 & 45445 & 9910 & 33907 & 3607 & $29568 \frac{c}{\circ}$ \\
\hline Standard error & 28294 & 23031 & 10712 & 2216 & 7582 & 806.4 & $6612 \bar{\varepsilon}$ \\
\hline $\begin{array}{l}95 \% \mathrm{Cl} \text { low } \\
\text { value }\end{array}$ & 96725 & 62331 & 29390 & 4987 & 27832 & 1530 & 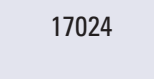 \\
\hline $\begin{array}{l}95 \% \mathrm{Cl} \text { high } \\
\text { value }\end{array}$ & 215168 & 158739 & 74589 & 14262 & 59570 & 4906 & $44701 \frac{1}{\frac{1}{2}}$ \\
\hline \multicolumn{7}{|c|}{ I, confidence interval; CMT, central memory T cells; EMT, effector memory T cells. } & 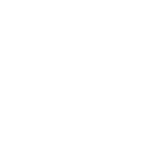 \\
\hline
\end{tabular}

this phenotype was carried out in both CD45RAt and CD45RO+ populations, to calculate the recently activated naive (CD45RA+) cells and the activated/memory (CD45RO+) cells after reactivation. The analysis of the cells with activation phenotype showed that in the populations of CD4+ and CD8+T cells, there was a discrete population of CD45RA+ and CD45RO+ cells expressing CD69 and sparse CRTAM+ cells (Fig. 2). It should be noted that no cells that coexpressed CD69 and CRTAM were detected (Fig. 2 and Table 6).

Considering that the samples came from $\mathrm{CHI}$, a sample from a patient with an acute Epstein-Barr virus (EBV) infection was also analyzed. In the CD4+ T cell population, within the CD45RA+ compartment, there was a 2.85-fold increase of CD69+cells (Figs. 2A and 2E), whereas, in the $\mathrm{CD} 45 \mathrm{RO}+$ population, this increase was of 2.1 times (Figs. 2B and 2F), compared with $\mathrm{CHI}$. On the other hand, within the CRTAM+ cells, a significant increase of approximately 8.9 times was observed in the CD45RA+ cells (Figs. 2A and 2E) and of 7.6-fold in the CD45RO+ population (Figs. $2 \mathrm{~B}$ and $2 \mathrm{~F}$ ) compared with the observed in $\mathrm{CHI}$. A significant difference that induces the activation of $T$ cells in the presence of an antigenic stimulus, the EBV, in this case, was observed.

In the case of CD8+ cells, an increase in those expressing CD69, both in the CD45RA+ (Figs. 2C and 2G) and in the CD45RO+ (Figs. 2D and 2H) populations was observed: 2.1 and 1.4 times, respectively. The CRTAM expression analysis showed an increase of 5.6 and 9.1 times in the CD45RA+ (Figs. $2 \mathrm{C}$ and 2G) and the CD45RO+ (Figs. 2D and 2H) populations, respectively. It is noteworthy that no cells expressing Both markers, CD69 and CRTAM, were detected in this sample. The analysis of the expression of CD69 and CRTAM showed an increase of 13.8 and 10.4 times in the CD45RA+ (Figs. $2 \mathrm{C}$ and $2 \mathrm{G}$ ) and CD45RO+ (Figs.2D and $2 \mathrm{H}$ ) populations, respectively.

The memory population analysis using the expression of molecules CD45RO, CCR7, and CD62L- allowed to define CMT and EMT subpopulations from the CD4+ and CD8+ cells compartments. The analysis showed that the CMT (CD45RO+ CD62L+ CCR7+) and EMT (CD45RO+ CD62L- CCR7-) population was represented by a median of 34.1 and 29.6 in the CD $4+T$ cells population (Table 3), and a median of $4 \%$ and $77.5 \%$ (Table 5 ) in the CD8+ T cells population, respectively. CMT and EMT populations percentage vatues were obtained from the $\mathrm{CD} 45 \mathrm{RO}+$ population.

The NK cells (CD16+ CD56+) determination and quantification (Figs. $3 \mathrm{~A}$ and $\mathrm{B}$ ) showed an average of $29.67 \%$, with a median of $28 \%$ (95\% Cl: $22-37.26 \%)$ in peripheral blood leukocytes (Table 7). The mean $\mathrm{NK}$ cells obtained value is higher compared to the reported 


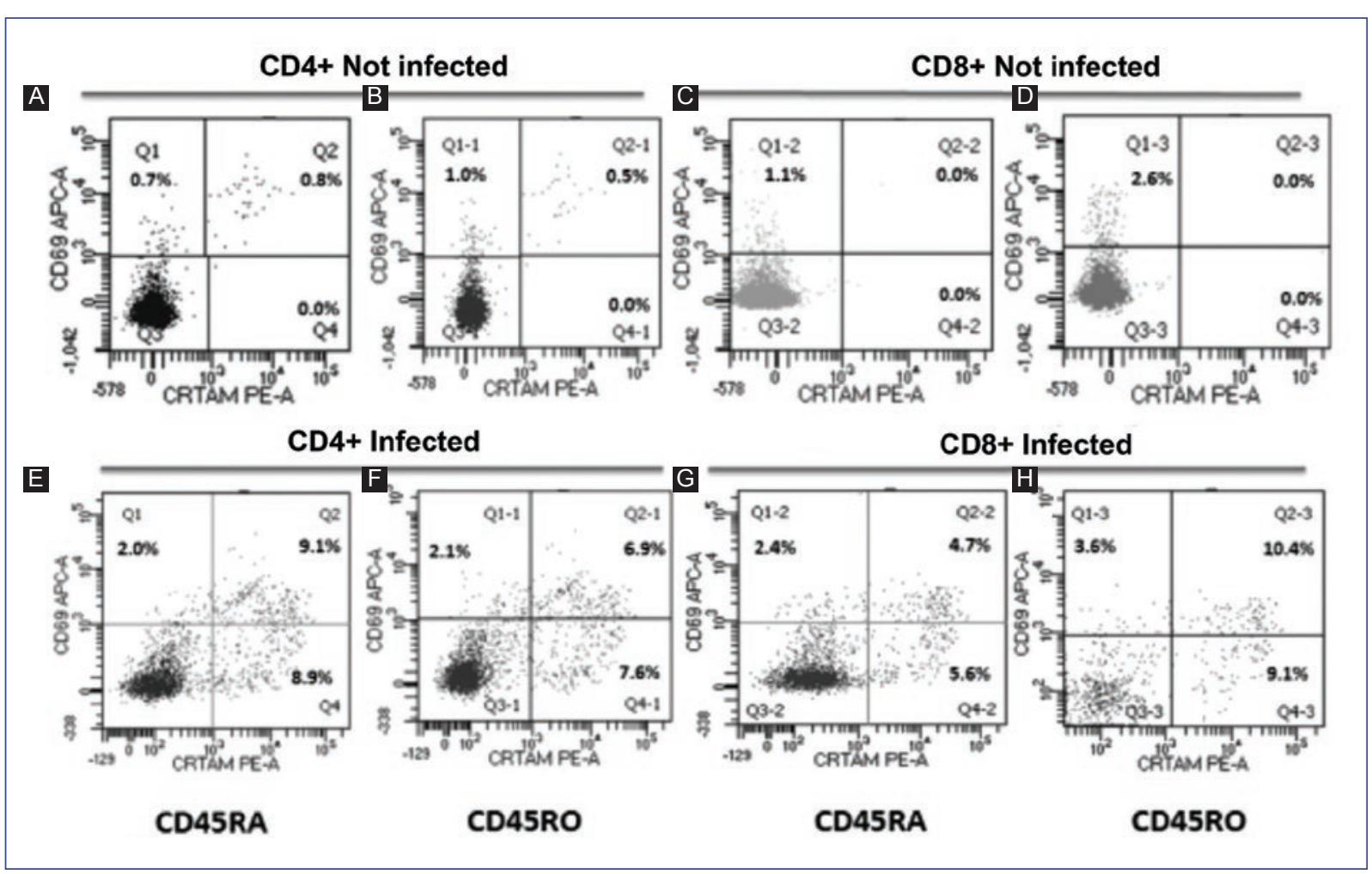

Figure 2. Phenotyping of the population of activated T lymphocytes. From CD4+ (A and E) and CD8+ (C and G) populations expressing the CD45RA molecule (naïve), the expression of CD69 and CRTAM (early activation markers) was analyzed. The same analysis was performed in the CD4+ CD45RO+ (B and F) and CD8+ CD45RO+ (D and H) populations representative sample of the clinically healthy individuals group (upper row) and an individual infected with the Epstein Barr virus (lower row).

in studies conducted in the Netherlands (mean of $14 \%$, $95 \% \mathrm{Cl}: 4-51 \%)^{27}$ and China (mean of $18 \%, 95 \% \mathrm{Cl}$ : 10.12- 28.34\%). ${ }^{28-30}$

\section{Discussion}

The characterization and quantification of the different $\mathrm{T}$ lymphocytes subsets in peripheral blood allowed us to know their distribution (absolute numbers and percentages) in $\mathrm{CHI}$. When analyzing the $\mathrm{CD} 3+\mathrm{T}$ cells, the use of CD45RA delimits bona fide the naivve cells within the CD4+ cell compartment. However, for the CD8+ compartment, it is necessary to use additional markers, such as CD62L and CCR7, if it is desired to identify the naïve population accurately. This significant difference should be considered when the interest of quantifying naivve cells is determinant in the patient's clinical follow-up, as it can be in the monitoring of hematopoietic progenitor cell receptors.

The difference between the percentages obtained in the present work compared with other reports mainly lies in the fact that the subpopulations were calculated in the parental population, meaning, CD45RA+CD4+ or CD8+ naïve, activated, effectors and CD45BO+ CD4+ or CD8+ TCM and TEM, and the absolute value was calculated based on total leukocytes.

The presence of activated cells is scarce in both CD45RA and CD45RO compartments for the CD4+ and CD8+ populations, as expected since no signs or symptoms associated with an acute infection were shown. Also, this observation is congruent with the discrete presence of effector cells. The detection of these cells in $\mathrm{CHI}$ is explained by the continuous contact with microorganisms (even in the absence of clinical signs and symptoms suggesting an acute infection), which induces the adaptive immune response and, after limiting the infection through its effector functions, produces its elimination by apoptosis. It should be noted that the frequency of effector cells is higher in the CD8+ population than in CD4+ cells.

The analysis of CMT and EMT populations in CD4+ cells showed a higher percentage of the former. In the 
索密

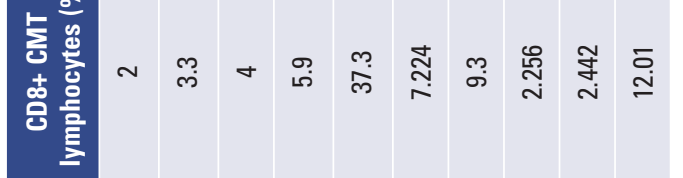

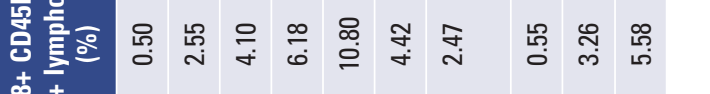
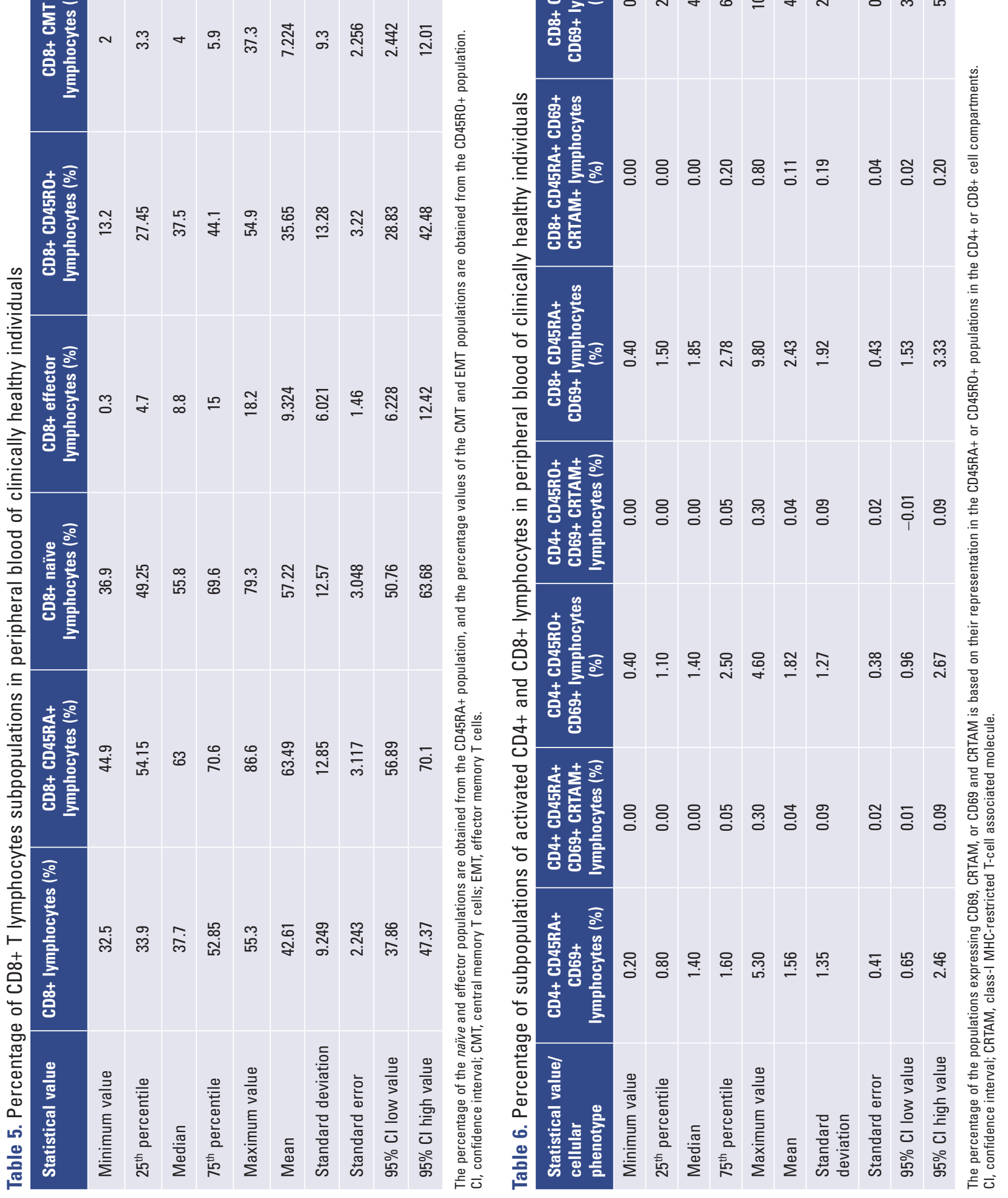


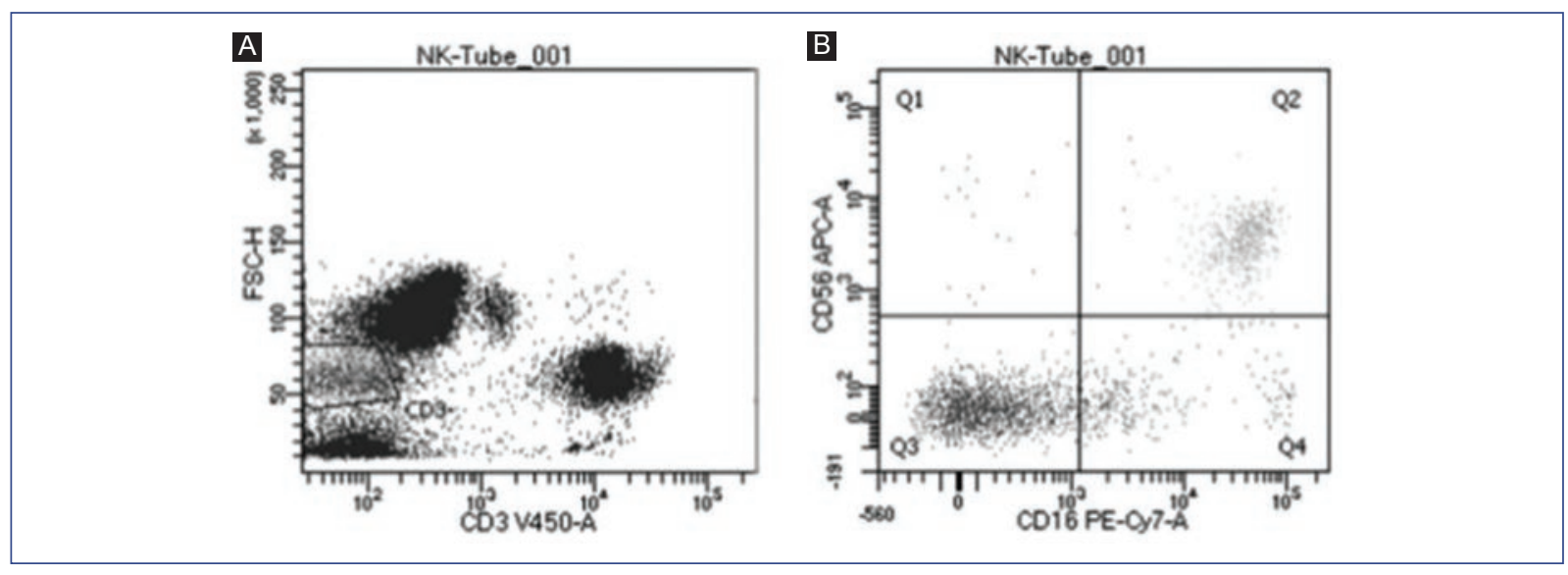

Figure 3. Identification of the natural killer cells in peripheral blood. From the region with living cells and the lymphoeyte morphology (small size and scarce granularity), the CD3- population was identified (A). From this population, the surface expression of the CD16 and CD56 molecules was analyzed for the identification of NK cells: CD16+ CD56+ (B). This group is a representative sample of clinically healthy individuals.

Table 7. Values of NK cells in peripheral blood of clinically healthy individuals

\begin{tabular}{|l|c|c|}
\hline Statistical value & NK cells (cell/ml) & NK cells (\%) \\
\hline Minimum value & 18,284 & 10.5 \\
\hline $25^{\text {th }}$ percentile & 28,313 & 18.8 \\
\hline Median & 58,177 & 28 \\
\hline $75^{\text {th }}$ percentile & 87,420 & 40.8 \\
\hline Maximum value & 130,597 & 51.1 \\
\hline Mean & 60,530 & 29.67 \\
\hline Standard deviation & 33,430 & 12.55 \\
\hline Standard error & 9,272 & 3.482 \\
\hline $95 \%$ Cl low value & 40,328 & 22.08 \\
\hline $95 \%$ Cl high value & 80,732 & 37.26 \\
\hline
\end{tabular}

$\mathrm{Cl}$, confidence interval; NK, natural killer.

case of CD8+ cells, a higher percentage of EMT compared with CMT is observed. In CD4+ cells, the presence of a CMT greater subpopulation would allow having a reservoir of EMT precursors to cooperate with the $B$ lymphocytes in the generation of antibodies and the performance of their effector capacity per se. In CD8 + cells, the EMT population is higher, which allows an earlier and more efficient performance (production of large quantities of cytokines in a short time) against intracellular infections, compared with those generated from activated naive cells. It is important to emphasize that the naive and memory populations change throughout life since the generation of naive T lymphocytes is thymus dependent, the number of peripheral naive population decreases as the organ involutes. ${ }^{5,31}$ The population of memory cells experiences modifications during their encounters with different pathogens, which modifies the repertoire and the subpopulations of CMT and EMT in the same compartment.

It is essential to establish an analysis system including the selection of the molecules that will define the populations of interest, as well as the determination of the percentages (relative to the lymphocytes population or total leukocytes) in each laboratory in which they wit be used as parameters for monitoring or single determination in peripheral blood samples. Thus, the different protocols used for the characterization of cell populations should be described in a way that they can be reproduced and not over-estimated, as in the case of the sole $^{2}$ use of CD45RA for defining the naive population. In this regard, significant variations have been described among users, equipment, staining methods, calculation of percentages and absolute numbers, which should be a crucial point when presenting information on the number and frequency in various cell groups. ${ }^{32,33}$

As this relationship is diminished, due to the increase of CD8+ T lymphocytes that act as effector cells of the immune system eliminating tumor cells or cells potentially infected by viruses, bacteria, or protozoa ${ }^{34}$, this is consistent with the status of the $\mathrm{CHI}$ participants.

Also, the presence of cells with an activation phenotype was determined, both in the subpopulation CD45RA+ and in CD45RO+, considering that the surface molecules CD69 and CRTAM are early markers 
that could be expressed in cells activated for the first time, namely naïve cells (CD45RA+), and in-memory cells $(\mathrm{CD} 45 \mathrm{RO}+)$ generated from the activation of naïve $T$ lymphocytes which responded to a stimulus, as the case of a viral ${ }^{35}$ or bacterial infection, or, the recognition of an alloantigen. ${ }^{36}$ The presence of cells with these characteristics (CD69+ CRTAM-, CD69+ CRTAM+, and CD69- CRTAM+) is almost inexistent in $\mathrm{CHI}$, both in the CD4+ and CD8+ $\mathrm{T}$ cells compartments, while being enhanced in an individual who was suffering from an acute viral infection. The transient expression of CD69 is a classic marker of early activation and, although CRTAM shares this characteristic, its expression during infection in vivo was unknown. The relevance of including a second activation marker, in addition to CD69, is that it allows an accurate calculation of the population of activated $T$ lymphocytes because the heterogeneous expression of both molecules allows distinguishing three activation phenotypes: CD69+ CRTAM-, CD69+ CRTAM+, and CD69-CRTAM+. It is not known if they belong to independent subpopulations generated during the activation, or they follow a line of differentiation. It would be essential to know the impact of each of the lines on the effector response (cytokine production and cytotoxic capacity), for example, during a viral infection.

The use of a panel of antibodies that allow the distinction of this population would be useful, specifically in those cases in which a clonal expansion associated with an infection or the rejection of a transplant (solid or hematopoietic progenitor cells) could be confused with a reconstitution of the $T$ cell compartment.

The information obtained from the $T$ lymphocytes phenotyping should be considered additional data provided by the clinical laboratory, which should be integrated into the patients' clinical characteristics, to their treatment, and the detection of viral or bacterial infections, among others. Their request should be considered in those situations in which the profile (phenotype and absolute number) of the naive, activated, effector or memory subpopulations within the CD4+ or CD8+ T lymphocyte compartments is required. This is very useful, for example, in individuals undergoing hematopoietic stem cell transplantation that need to be monitored to establish the treatment success, as well as in individuals in whom the identification of specific subpopulations could support the identification of deficiencies within the T cells subpopulations associated with the presence of recurrent infections or low protective immune response after vaccination.
It should be considered that the cellular populations and subpopulations in the $\mathrm{T}$ cell compartment are in dynamic homeostasis, depending on the number of known antigenic events to which the individual thas been exposed: vaccination, contagion of known infections, determined infections or those produced by unknown agents that generated an immune response, in addition to age. ${ }^{37}$ For this reason, data from T Iymphocyte subpopulations should be interpreted individually, taking as reference the $T$ lymphocyte subpopulations in the same individual, before or after clinical or therapeutic intervention. In this way, the heterogeneityooserved in subpopulations between individuals could be counteracted.

In the case of NK cells, similar values to those reported in the literature ${ }^{38}$ were observed, and the definition of the CD3- CD16+ CD56+ population was clearly delimited, so it could also be used as an additional data in the profile characterization of cells with cytotoxic capacity.

With the standardization of a panel for characterizing subpopulations of naïve, activated, effector and memory $T$ cells in peripheral blood, and the knowledge of the distribution of this group of cells in $\mathrm{CHI}$, it Was demonstrated that this tool is useful and capabte of indicating differences in subpopulations of activated and effector cells in the presence and absence of an antigenic stimulus (in this case, a viral infection). necessary to continue with the inclusion of a largerand more homogeneous sample to evaluate the values, of each of the subpopulations and detect any alteration that deserves a detailed analysis, or to follow upsthe individuals in whom the use of this panel could defect variations useful for the clinical team to make therapeutic decisions, and even serve in monitoring their progress and the treatment efficacy.

In conclusion, a panel was standardized for the characterization of subpopulations of naïve, activated effector, and memory T cells, as well as NK cells in peripheral blood, using flow cytometry (eight-color $\mathrm{BD}$ FACS CANTO $\|^{\circledR}$ cytometer). This panel will be useful to follow up patients who require frequent assessments of their immunological status from the cellular perspecetive, and for patients in whom it is necessary to evaluate their immune reconstitution, particularly the $\mathrm{T}$-cell lineage.

\section{Ethical disclosures}

Protection of human and animal subjects. The authors declare that no experiments were performed on humans or animals for this study. 
Confidentiality of data. The authors declare that they have followed the protocols of their work center on the publication of patient data.

Right to privacy and informed consent. The authors declare that no personal data of patients appear in this article. Participants were informed of the protocol characteristics, as well as the minimum risk to which they would be subjected to obtain the samples. The authors have obtained the written informed consent of the patients or subjects mentioned in the article. The corresponding author is in possession of this document.

\section{Conflicts of interest}

The authors declare that they have no conflicts of interest.

\section{Funding}

The present study was approved by the Comite de Ética e Investigación of the Hospital Infantil de México Federico Gómez taking into account the international documents, such as the Declaration of Helsinki and the Belmont Report, and public documents, such as the Ley General de Salud and the NOM-012-SSA3-2012. This protocol is part of the HIM/2017/038 project.

\section{References}

1. Goldsby K. Inmunología. Mexico: McGraw Hill; 2004.

2. Abbas AK, Lichman AH PS. Immunología celular y molecular. Barcelona: Elsevier Saunders; 2015.

3. Appay V, Sauce D. Naive T cells: the crux of cellular immune aging? Exp Gerontol. 2014;54:90-3.

4. Taub DD, Longo DL. Insights into thymic aging and regeneration. Immunol Rev. 2005;205:72-93.

5. Linton PJ, Dorshkind K. Age-related changes in lymphocyte development and function. Nat Immunol. 2004;5:133-9.

6. Qi Q, Zhang DW, Weyand CM, Goronzy JJ. Mechanisms shaping the naïve $T$ cell repertoire in the elderly-thymic involution or peripheral homeostatic proliferation? Exp Gerontol. 2014;54:71-4.

7. Medina-Contreras O, Soldevila G, Patiño-Lopez G, Canche-Pool E, Valle-Rios R, Ortiz-Navarrete V. Role of CRTAM during mouse early $T$ lymphocytes development. Dev Comp Immunol. 2010;34:196-202.

8. Wong SH, Vannberg FO, Spencer AJ, van der Weyden L, Hill AVS, Wyllie DH. CRTAM confers late-stage activation of CD8+ T cells to regulate retention within lymph node. J Immunol. 2010;184:4052-3.

9. Beristain-Covarrubias N, Canche-Pool EB, Ramirez-Velazquez C, Barragan-Galvez JC, Gomez-Diaz RA, Ortiz-Navarrete V. Class I-restricted $\mathrm{T}$ cell-associated molecule is a marker for IFN- $\gamma$-producing iNKT cells in healthy subjects and patients with type 1 diabetes. J Interferon Cytokine Res. 2017;37:39-49.

10. Calabresi PA, Allie R, Mullen KM, Yun SH, Georgantas RW, Whartenby KA. Kinetics of CCR7 expression differ between primary activation and effector memory states of $T(H) 1$ and $T(H) 2$ cells. J Neuroimmunol. 2003;139:58-65.

11. van Leeuwen EMM, van Buul JD, Remmerswaal EBM, Hordijk PL, ten Berge IJM, van Lier RAW. Functional re-expression of CCR7 on CMV-specific CD8+T cells upon antigenic stimulation. Int Immunol. 2005;17:713-9.
12. Krammer PH, Arnold R, Lavrik IN. Life and death in peripheral T cells. Nat Rev Immunol. 2007;7:532-42

13. Mahnke YD, Brodie TM, Sallusto F, Roederer M, Lugli E. The who's who of T-cell differentiation: human memory T-cell subsets. Eur J Immunol. 2013;43:2797-809.

14. Weninger $W$, Manjunath $N$, von Andrian UH. Migration and differentiation of CD8+ T cells. Immunol Rev. 2002:186:221-33.

15. Lanzavecchia A, Sallusto F. Understanding the generation and function of memory T cell subsets. Curr Opin Immunol. 2005;17:326-32.

16. Zanetti M, Franchini G. T cell memory and protective immunity by vaccination: is more better? Trends Immunol. 2006;27:511-7.

17. Sallusto F, Lenig D, Förster R, Lipp M, Lanzavecchia A. Two subsets of memory $T$ lymphocytes with distinct homing potentials and effectorfunctions. Nature. 1999;401:708-12.

18. Bøyum A. Isolation of lymphocytes, granulocytes and macrophages. Scand J Immunol. 1976; Suppl 5:9-15.

19. Brain P, Gordon J, Willetts WA. Rosette formation by peripheral lymphocytes. Clin Exp Immunol. 1970;6:681-8.

20. Bonner WA, Hulett HR, Sweet RG, Herzenberg LA. Fluorescence-activated cell sorting. Rev Sci Instrum. 1972;43:404-9.

21. Appay V, van Lier RAW, Sallusto F, Roederer M. Phenotype and fühction of human T lymphocyte subsets: consensus and issues. Cytometry $A$. 2008;73:975-83.

22. Corneau A, Cosma A, Even S, Katlama C, Le Grand R, Frachet V et al. Comprehensive mass cytometry analysis of cell cycle, activation, and coinhibitory receptors expression in CD4 T cells from healthy and HIV-infected individuals. Cytom Part B Clin Cytom. 2017;92:21-32.

23. Siegel RL, Fox RW. A longitudinal study of a patient with acquired immunodeficiency syndrome using $T$ cell subset analysis. Adv Exp-Med Biol. 1983;166:295-303.

24. Toubert A, Clave E, Talvensaari K, Douay C, Charron D. New tools in assessing immune reconstitution after hematopoietic stem cell transplantation. Vox Sang. 2000;78:29-31.

25. Santagostino A, Garbaccio G, Pistorio A, Bolis V, Camisasca G, Paggliaro $P$, et al. An Italian national multicenter study for the definition of reference ranges for normal values of peripheral blood lymphocyte subsets in healthy adults. Haematologica. 1999;84:499-504.

26. Flores MGP, Vázquez MIC, Camaño MEV, Bayardo RLG, Contrerás FO, Galicia Tapia J, et al. Determinación de concentraciones de subpoblaciones de linfocitos en donadores adultos sanos del CMN 20 de Noviembre, ISSSTE. Rev Espec Médico-Quirúrgicas. 2013;18:228-34.

27. Schatorjé EJH, Gemen EFA, Driessen GJA, Leuvenink J, van-Hout RWNM, de Vries E. Paediatric reference values for the peripheral cell compartment. Scand J Immunol. 2012;75:436-44.

28. Jiang $Y$, Zhang $L$, Wen D, Ding $Y$. Role of physical and chemicafinteractions in the antibacterial behavior of $\mathrm{ZnO}$ nanoparticles against ${ }^{\bar{E}} \bar{E}$ coli. Mater Sci Eng C Mater Biol Appl. 2016;69:1361-6.

29. Lin C, Shao B, Zhou Y, Niu X, Lin Y. Maternal high-fat diet influences stroke outcome in adult rat offspring. J Mol Endocrinol. 2016;56:101-12.

30. Ding Y, Zhou L, Xia Y, Wang W, Wang Y, Li L, et al. Reference talues for peripheral blood lymphocyte subsets of healthy children in China. J Allergy Clin Immunol. 2018;142:970-3.

31. Jiao Y, Qiu Z, Xie J, Li D, Li T. Reference ranges and age-related changes of peripheral blood lymphocyte subsets in Chinese healthy adults. Sci China Ser C Life Sci. 2009:52:643-50.

32. Rivadeneyra-Espínoza L, Pérez-Romano B, González-Flores A, Guzmán-García MO, Carvajal-Armora F, Ruiz-Argüelles A. Instrumentz and protocol-dependent variation in the enumeration of CD34+ cells by flow cytometry. Transfusion. 2006;46:530-6.

33. Ruiz-Argüelles A, Pérez-Romano B. Immunophenotypic analysis of peripheral blood lymphocytes. Curr Protoc Cytom. 2000;11:6.5.1-14.

34. Ahmed R, Gray D. Immunological memory and protective immunity: understanding their relation. Science. 1996;272:54-60.

35. Griffiths SJ, Riddell NE, Masters J, Libri V, Henson SM, Wertheimer A, et al. Age-associated increase of low-avidity cytomegalovirus-specific CD8+ T cells that re-express CD45RA. J Immunol. 2013;190:5363-72.

36. Akbar AN, Salmon M, Ivory K, Taki S, Pilling D, Janossy G. HEman CD4+CD45R0+ and CD4+CD45RA+ $T$ cells synergize in response to alloantigens. Eur J Immunol. 1991;21:2517-22.

37. Clement LT. Isoforms of the CD45 common leukocyte antigen family: markers for human T-cell differentiation. J Clin Immunol. 1992;12.9-10.

38. Bisset LR, Lung TL, Kaelin M, Ludwig E, Dubs RW. Reference valuess for peripheral blood lymphocyte phenotypes applicable to the healthy adult population in Switzerland. Eur J Haematol. 2004;72:203-12. 